\title{
Inflexões educomunicativas
}

Adilson Citelli

Professor titular do Departamento de Comunicações e Artes da ECA/USP, onde ministra cursos de graduação e pós-graduação. Orienta dissertações e teses nas áreas de Comunicação e Linguagem, com ênfase nas subáreas Comunicação/Educação, Comunicação/Linguagem. É coeditor da revista Comunicação \& Educação, bem como pesquisador $1 C$ do CNPQ. É autor de inúmeros artigos e livros, dentre os quais se destacam: Linguagem e persuasão (Ática, 1994); Comunicação e Educação: a linguagem em movimento (Senac, 2000); Palavras, meios de comunicação e educação (Cortez: 2006); Educomunicação: construindo uma nova área de conhecimento (org. com Cristina Costa, Paulinas, 2011).

E-mail: citelli@uol.com.br

Resumo: $\mathrm{O}$ autor procura mostrar como as relações comunicação/educação passam a fazer parte dos espaços escolares. Nesse sentido, evidencia questões afeitas a certos conceitos de modernização ou dos embates envolvendo a entrada das novas tecnologias no universo educativo formal. Por fim, são apresentados os artigos e seções que fazem parte deste número da Revista.

Palavras-chave: Escola, novas tecnologias, educomunicação.
Abstract: The author shows how the relations between communication and education became part of the school spaces. In this sense, highlights questions related to specific concepts of modernization or about the clashes involving the introduction of new technologies in formal educational universe. Finally, presents the articles and sections that are part of this issue of the magazine.

Keywords: School, new technologies, educommunication.

A exigência de emancipação parece ser evidente numa democracia.

Theodor Adorno

Os vínculos entre comunicação e educação conhecem, ao menos nos últimos vinte anos, desenvolvimento singular, pois, calcados nas possibilidades abertas por tecnologias que ou foram modificadas em seus projetos originais ou promoveram novos padrões e sistemas de transporte de sons e imagens, permitem a criação de inúmeras alternativas geradoras de informação e conhecimento, com resultados importantes para as dinâmicas sociais. E disto servem, como ilustração recente, as ocorrências no mundo árabe nos inícios de 2011, com a derrubada de ditaduras instaladas há décadas e para as quais a internet, o twitter, os blogs, as redes sociais tiveram papel - conquanto não único - importante no que diz respeito à mobilização dos jovens e opositores dos regimes vigentes naquela parte do planeta.

A difusão dos computadores, da internet, dos tablets, para indicarmos alguns dos suportes que tiveram entrada nas salas de aula, facultou aos docentes e discentes não apenas empreender outras estratégias de acesso ao conhecimento e à informação, como forçou o aparato educativo a reconstituir e reposicionar 
as relações de ensino-aprendizagem. Parece desnecessário arrolar, no momento, o conjunto de novos dispositivos que passaram a fazer parte, de maneira direta ou indireta, dos ambientes escolares.

Tal processo deve demandar análise mais fina, pois os vínculos da educação formal com aqueles dispositivos de comunicação demonstram aspectos positivos e, também, uma série de problemas. Ao lado das facilidades permitidas pelo crescimento no número de usuários dos computadores, da www, da telefonia celular, parte deles sendo levados às escolas públicas brasileiras em programas oficiais ou de organizações não governamentais, prosseguem as conhecidas carências da educação formal. Vale dizer, estamos marcados por claudicante conceito de modernização, termo, aliás, proferido sem muito critério quando está em causa pensar os liames entre padrões tecnológicos e apropriação social do conhecimento processado nas salas de aula.

Otília Beatriz Fiori Arantes e Paulo Eduardo Arantes, ao insistirem no caráter complexo de nossa modernização - malgrado o lusco-fusco retórico existente sobre ela -, concluem que, em países periféricos como o nosso, o atraso não se depreende do avant-garde, constituindo moeda de face única. E afirmam:

Basta enumerar todas as "figuras" da nossa modernidade plena (não houve nenhum desvio, nenhum encalhe no "atraso"): começamos com uma economia primário-exportadora; depois país subdesenvolvido e mais adiante em desenvolvimento; logo a seguir, com o "milagre" autoritário, um novo país industrializado, de cultura inflacionária, e logo depois expulso do circuito financeiro mundial; readmitido na condição de mercado emergente (veja que não somos nem nunca fomos um "país", mas um mercado, e por isso absolutamente "moderno") e, nesta condição, em rota para uma economia primário-importadora, ou dito tecnicamente, e estou quase citando, somos uma plataforma de expansão comercial, mais exatamente um circuito auxiliar de valorização patrimonial do capital financeiro mundial [... $]^{1}$.

Tomada em sua perspectiva maior, a inflexão crítica sobre o modo de inserção nos chamados processos modernizadores faz sentido histórico pelas conhecidas contradições que rondam a sociedade brasileira e a inclusão do país na economia mundial. Olhando o problema, contudo, pelo recorte de nossa preocupação central, é imperioso reconhecer que a dupla educação formal e novas tecnologias - uma das vertentes da modernização - apresentam singularidades que se espraiam seja na questão do acesso propriamente dito aos dispositivos de comunicação, seja na orientação do sensório das gerações mais jovens. Noutros termos, os circuitos do aprendizado devem ancorar-se não apenas nas metodologias tradicionais - sem atribuir ao termo nenhuma carga negativa, apenas sinalizando um tipo de práxis de que servem como exemplos os procedimentos enciclopédicos e transmissivos -, mas podem ser ampliados tendo em mira o conjunto de possibilidades que se abrem para o acesso ao conhecimento e à informação.

Claro está que, neste caso, como já se havia verificado nos debates envolvendo os usos dos meios de comunicação para educação popular, conforme os finais dos anos 1950 e inícios de 1960, e mesmo no período da ditadura 
militar, articulam-se posições que oscilam segundo compreensões ideológicas e mesmo referentes ao próprio modo de acionar os dispositivos midiáticos para fins educativos. Expressões como tecnicismo e tecnofobia circulam livremente na cena discursiva dos envolvidos com as questões educacionais.

Para uns, a entrada dos meios de comunicação na sala de aula, compreendendo tanto os computadores como outros suportes digitais, esclarece a falsa superação de um conjunto de problemas crônicos que persistem no sistema escolar, haja vista as precárias condições de trabalho dos professores e da formação qualificada dos estudantes. O usufrutuário maior da ação "modernizadora" seria a indústria eletrônica, com a sua imensa capacidade de gerar obsolescência de padrões tecnológicos e consequente exigência para os seguidos programas governamentais de mudança de equipamentos nas escolas.

Para outros, as instituições educativas encarnam o medo de enfrentar os desafios propostos pelo mundo contemporâneo, em sua complexidade sociotécnica. Tal desencontro marcaria os fluxos organizativos da rede escolar em seus variados aspectos administrativos, gerenciais, funcionais. Daí evidenciar-se um misto de privação material e desacerto na cultura institucional, que teria no professor alguém mais voltado a manter procedimentos sancionados pela tradição didático-pedagógica e menos desejoso de promover experiências e estratégias educativas equânimes aos novos cenários sociotécnicos. O resultado deste ajustamento pouco atraente seria a montagem de um quadro em que o jovem estudante, marcado em seu cotidiano pelas referências da sociedade digital, revelaria baixo engajamento e interesse no atinente aos propósitos da escola.

A questão, entretanto, não reside num jogo opositivo entre defensores ou opositores das aproximações entre comunicação e educação. Como propugnavam os latinos, in media res. A virtude está no meio. O sistema escolar pode e deve proceder à incorporação do potencial oferecido pelas tecnologias, sejam elas digitais ou não - sem com isto cair no reducionismo tecnicista -, ao mesmo passo em que se envolve em programas de revalorização dos educadores, em atividades dentro e fora da sala de aula, criando condições para aberturas no processo didático pedagógico, nas relações ensino-aprendizagem. Posto de outra maneira, é imperativo ajustar políticas públicas orientadas para o reconhecimento do papel estratégico da educação formal - no que isto significa de alocação de recursos, valorização do professor, promoção de alternativas com vistas à permanência estudantil etc., como estímulo à criação, implantação, avaliação dos projetos pelas unidades escolares -, mecanismo capaz de levar ao envolvimento de alunos, pais, professores em torno de objetivos afeitos às realidades que sustentam as salas de aula. É no interior destes poucos pontos exemplificadores que devem ser formuladas as perguntas: aulas expositivas, trabalhos em grupo, exercícios de memorização, uso de computadores, realização de vídeos, elaboração de programas de rádio etc., por quê, para quê? E só depois de se proceder às respostas discutidas e negociadas pelos envolvidos nos processos educativos, ir às compras do vasto arsenal que inclui os notebooks, as TVs de plasma, os tablets. Tudo indica residir no aprofundamento destas questões o 
comunicação \& educação • Ano XVII • número 1 • jan/jun 2012

desafio para se trabalhar com os dispositivos técnicos nos espaços escolares, sem com isto incorrer em respostas estereotipadas ou procedimentos açodados que nem sempre atendem aos fins últimos da educação formal.

Em um momento em que o Departamento de Comunicações e Artes, da Escola de Comunicações e Artes da USP, se prepara para receber uma nova turma de ingressantes na sua Licenciatura em Educomunicação, os textos a seguir ajudam a pensar nas múltiplas implicações envolvidas no campo que inter-relaciona comunicação e educação.

\section{ARTIGOS NACIONAIS}

O primeiro dos quatro artigos nacionais selecionados para este número da Revista, elaborado por Brasilina Passarelli, Antonio Helio Junqueira e Rodrigo Eduardo Botelho Francisco, intitulado Netnografia no Programa de Inclusão Digital AcessaSP, mostra como ocorrem determinados vínculos entre as TICs e as novas modalizações socioculturais, tendo como referência o programa de inclusão digital de idosos desenvolvido no Estado de São Paulo e como procedimento metodológico a netnografia.

Em Rádio comunitária construindo o Capital Social: mulheres rurais na produção radiofônica, Ivanice Oliveira de Lima e Maria Salett Tauk Santos analisam a produção da rádio comunitária alternativa FM pelas mulheres envolvidas com a ONG Associação das Mulheres de Nazaré da Mata (AMUAN), em Pernambuco.

No texto Roland Barthes diante do signo fotográfico, Leda Tenório da Motta e Rodrigo Fontanari retomam o conhecido livro do pensador francês, com o intuito de ampliar o debate acerca do signo fotográfico e mostrar a atualidade do pensamento barthesiano no que diz respeito à análise do lugar ocupado pelas imagens técnicas no mundo contemporâneo.

Por fim, em Revisitando Morin: os novos desafios para os educadores, um grupo de estudantes de mestrado e doutorado, sob coordenação da Profa. Dra. Lucilene Cury, procede à leitura de algumas obras de Edgard Morin, buscando, a partir delas, entender o papel desempenhado pelas novas tecnologias de informação e da comunicação nos processos educativos.

\section{ARTIGOS INTERNACIONAIS}

O professor Giovanni Bechelloni, da Universidade La Sapienza de Roma, no artigo Contando e compartilhando narrativas acadêmicas sobre a boa comunicação, reflete sobre o papel da comunicação em nosso tempo. Para tanto considera as mudanças ocorridas, sobretudo, no mundo mediterrâneo, a partir da $2^{a}$ Guerra Mundial, e os processos de fragmentação social, desterritorialização e multipolaridade política e econômica. E aduz a ideia segundo a qual, neste cenário, o próprio conceito de comunicação precisa ser reposicionado.

Em Brinquedo, memória de uma sociedade, a professora do Instituto Uruguaio de Educação pela Arte, Josseline Cabanne, faz interessante vínculo entre 
identidades culturais e brinquedos. Nesse sentido, através da presença ou ausência de objetos lúdicos, com a sua carga simbólica e histórica, perdem-se ou acentuam-se determinadas marcas de pertencimento social.

\section{ARTIGO DE GESTÃO}

A especialista em Gestão da Comunicação, Juliana Winkel, em Tradição e mudança: os desafios da afirmação de marca na Andreato Comunicação e Cultura, examina como uma empresa voltada à área da comunicação enfrenta os desafios suscitados pelas novas mídias. Desse modo, a autora examina a transição entre modelos modernos e pós-modernos de gerenciamento, tendo por objeto o estúdio do artista gráfico Elifas Andreato.

\section{ENTREVISTA}

O entrevistado deste número da Comunicação $\mathcal{E}$ Educação é Daniel Prieto Castillo. Considerado uma das maiores autoridades latino-americanas nos estudos de comunicação/educação e comunicação para o desenvolvimento, o argentino, professor na Universidade Nacional de Cuyo, em Mendoza, publicou uma série de livros e artigos no campo de interesse da nossa Revista. Aproveitando a presença de Daniel Prieto no Congresso Internacional de Educación mediática y competencia digital, ocorrido em Segóvia, Espanha, em outubro de 2011, uma equipe da Comunicação $\mathcal{E}$ Educação, de que faziam parte Adilson Citelli, Roseli Fígaro e Izabel Leão, que lá estava para participar de atividades acadêmicas, realizou a entrevista. O material foi editado por Izabel Leão.

\section{CRÍTICA}

A professora, dramaturga, escritora e poeta Renata Pallottini, no artigo $O$ personagem na ficção policial moderna, situa a obra do ficcionista Leonardo Padura Fuentes, mostrando como nele se articulam a narrativa policial e determinadas características da sociedade do seu país, Cuba.

\section{DEPOIMENTO}

Quem conta sua trajetória a Comunicação Ẽ Educação é Marina Rosenfeld, Gerente do Núcleo de Comunicação Comunitária da Associação Cidade Escola Aprendiz, organização que congrega escolas, comunidade e setor público em ações comunicativas em diversas partes do país. Neste Depoimento, Marina conta como passou de estudante interessada em ações de Educomunicação a Coordenadora do mesmo projeto em que começou a atuar como jovem voluntária, na década de 1990. 
comunicação \& educação • Ano XVII • número 1 • jan/jun 2012

\section{EXPERIÊNCIA}

Roseane Andrelo e Marcele Tonelli de Oliveira apresentam, em Mídia-educação: da criatividade à livre expressão na escola, o trabalho que realizaram junto a alunos do ensino médio em uma escola pública de São Paulo, voltado a desenvolver metodologias para a leitura e produção de conteúdos em som e imagem.

\section{POESIA}

Adilson Citelli e Cristine Vargas selecionaram alguns poemas escritos por Ana Cristina Cesar. Uma das representantes da poesia inovadora surgida nos anos 1970, Ana C. produziu textos marcados pela pesquisa de linguagem, pela ironia, pela fragmentação e pela inquietude própria daquela geração que cresceu sob o jugo da ditadura militar. A sua morte prematura deixou lacuna importante na cena literária brasileira.

\section{RESENHAS}

Maria Cristina Palma Mungioli apresenta o livro Ficção televisiva transmidiática no Brasil: plataformas, convergência, comunidades virtuais, organizado por Maria Immacolata Vassalo de Lopes. Nesta obra, são apresentados os resultados de pesquisas em teledramaturgia, televisão e comunicação realizadas por equipes brasileiras e estrangeiras organizadas em torno da rede Obitel (Observatório Ibero-Americano de Ficção Televisiva).

Maria Ignês Carlos Magno comenta o filme $O$ contador de histórias, de Luiz Villaça. A obra traz a vida de Roberto Carlos Ramos, que de interno da antiga Febem se tornou pedagogo e contador de histórias. Neste percurso, assistimos à superação de um contexto de violência e marginalidade e de uma aposta no potencial da educação, da criatividade e da imaginação.

Ismar de Oliveira Soares e Benedita Almeida discutem a recente publicação de Heloisa Dupas Penteado e Elsa Garrido, que possui o título de Pesquisa-ensino: a comunicação escolar na formação do professor. A obra, publicada em 2010, foi escolhida pela Câmara Brasileira do Livro como um das melhores na categoria Educação. O livro expõe uma pesquisa envolvendo o ensino, considerando a comunicação e o diálogo como elementos fundamentais para a constituição do processo educativo.

\section{ATIVIDADES EM SALA DE AULA}

Ruth Ribas Itacarambi propõe projetos pedagógicos a serem desenvolvidos em sala de aula com alunos do ensino fundamental e médio, utilizando artigos publicados nesta edição da Revista. 